\title{
BRECHAS POLIFÁSICAS DA BORDA NOROESTE DA BACIA DO GUARATUBINHA, SUDESTE DO PARANÁ
}

\section{POLIPHASIC BRECCIAS AT THE NORTHWEST BORDER OF GUARATUBINHA BASIN, SOUTHEAST OF PARANA STATE, BRAZIL}

\author{
Leonardo Mairink BARÃO ${ }^{1}$, Barbara TRZASKOS ${ }^{2}$ \\ ${ }^{1}$ Programa de Pós-Graduação em Geologia, Universidade Federal do Paraná - UFPR - Centro Politécnico. Curitiba, Paraná, Brasil. \\ Emails: leobaraogeo@gmail.com; leonardobarao@ufpr.br \\ ${ }^{2}$ Departamento de Geologia, Setor de Ciências da Terra, Universidade Federal do Paraná - UFPR - Centro Politécnico. Curitiba, \\ Paraná, Brasil. Emails: barbaratrzaskos@gmail.com; barbaratrzaskos@ufpr.br
}

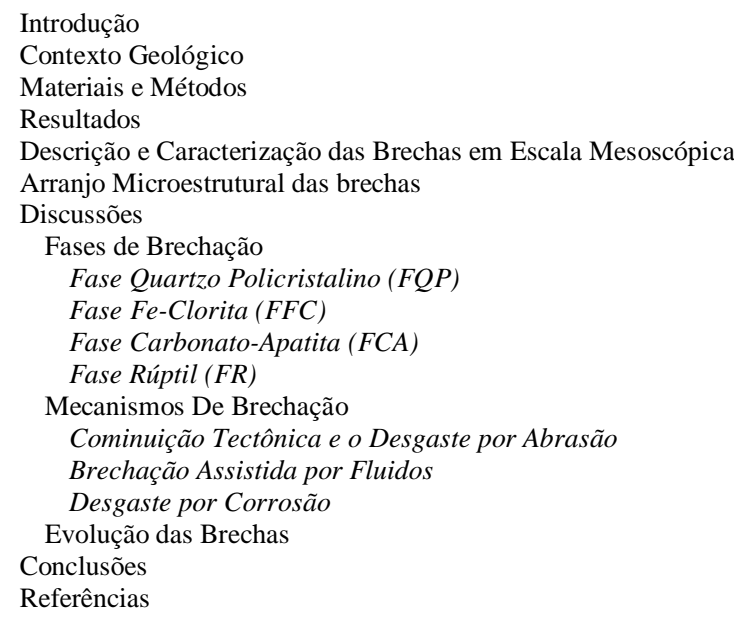

RESUMO - As rochas brechadas, identificadas na borda noroeste da Bacia do Guaratubinha, estão restritas aos riolitos do Membro Escutador, Formação Serra do Salto. A unidade foi submetida a três eventos de deformação, sendo o primeiro evento (E1) relacionado a intenso tectonismo e hidrotermalismo. O presente trabalho tem por objetivo caracterizar as rochas de falha hidrotermalizadas associadas aos derrames riolíticos na Bacia do Guaratubinha. A definição dos mecanismos de deformação foi baseada na descrição microestrutural de amostras orientadas coletadas no núcleo e nas bordas dos planos de falha reconhecidos. Os corpos brechóides possuem espessura de até $1 \mathrm{~m}$, e apresentam feições de cominuição, desgaste por abrasão, brechação assistida por fluidos e desgaste por corrosão, indicando que a deformação e o hidrotermalismo concentraram-se ao longo dos planos de falha. Estes planos serviram de conduto para percolação de fluidos tardios, esses foram essenciais para formação da trama estrutural das brechas.

Palavras-chave: Hidrotermalismo, rochas de falha, mecanismos de brechação.

ABSTRACT - Brecciated rocks identified along the northwestern border of the Guaratubinha Basin are strictly associated to rhyolites that compose the Escutador Member, within the Serra do Salto Formation. This unit was affected by three deformational events, and the first one (E1) is related to a phase of intense tectonism and hydrothermalism. The present paper aims to characterize fault-related, hydrothermalized rocks associated to rhyolitic floods that took place in the Guaratubinha Basin. The definition of deformation mechanisms was based on a microstructural description of oriented samples, which were collected in the cores and along the borders of the recognized fault-planes. The identified breccia-like bodies display thicknesses up to $1 \mathrm{~m}$, and are characterized by comminution features, wear abrasion, and fluids-assisted brecciation by and wear abrasion. These characteristics indicate that hydrothermalism and deformation were concentrated along fault planes. Consequently, these planes acted as conduits for the percolation of late-stage fluids, which were essential components for the formation of the structural arrangement of the breccias.

Keywords: Hydrothermalism, fault rocks, brecciation mechanisms.

\section{INTRODUÇÃO}

A caracterização de rochas de falha tem por objetivo determinar os mecanismos de deformação em zonas de cisalhamento formadas na crosta superior (Sibson, 1977). Esta deformação pode estar associada a processos de cominuição mecânica, relacionada ao atrito entre os blocos deslocados, ou ao processo de fraturamento hidráulico. A temperatura e a percolação de fluidos exercem importante papel no processo de deformação, contribuindo para o processo de brechação química ao longo dos planos de falha.
Os eventos deformacionais registrados na Bacia do Guaratubinha estão relacionados à tectônica strike-slip, sendo o primeiro evento, E1 aquele que deixou significativos registros de deformação rúptil, com destaque às rochas brechadas (Barão et al., 2017). A análise estrutural realizada na área indica que o evento de deformação E1 ocorreu como fase tardia ao vulcanismo riolítico presente na Bacia. Estas rochas de falha, geradas em profundidade entre 10 - $15 \mathrm{~km}$, foram classificadas como brechas de falha da série dos cataclasitos, segundo a 
porcentagem de matriz observada (Sibson, 1977). Esse tipo de brecha é descrito por Jébrak (1997), que leva em conta a formação de brechas hidrotermais ao longo de veios mineralizados.

O processo de brechação e as estruturas de corrosão identificadas são semelhantes aos descritos por diversos autores (e.g. Sibson, 1986; Laznicka, 1988; Jébrak 1997; Lorilleux et al., 2002). O presente trabalho tem por objetivo caracterizar as feições microestruturais das brechas de falha identificadas em riolitos da Bacia do Guaratubinha e discutir as evidências da atuação de fluidos hidrotermais destes planos.

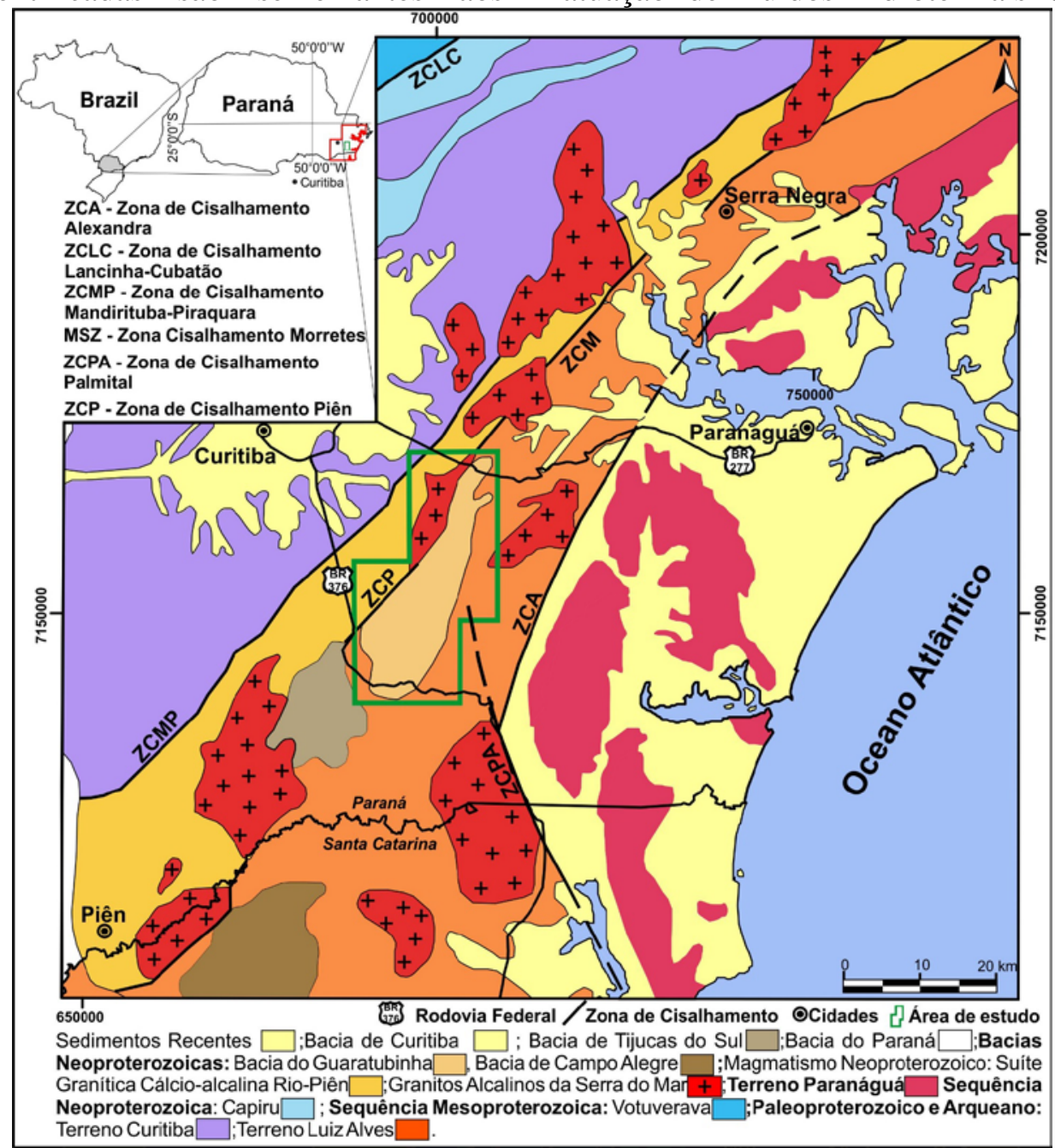

Figura 1. Mapa geológico simplificado da região sul do Brasil com a indicação das principais zonas de cisalhamento. Marcando a Bacia do Guaratubinha sobre o Terreno Luiz Alves (Modificado de Basei et al. 1990; Siga Jr. 1995).

\section{CONTEXTO GEOLÓGICO}

A Bacia do Guaratubinha é definida com uma das bacias do estágio de transição da Plataforma Sul-Americana (Almeida, 1969; Teixeira et al., 2004), formada ao final do Neoproterozoico e

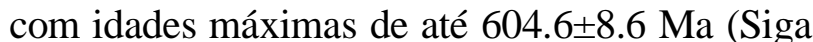
Jr. et al., 2000). A Bacia possui área de aproximadamente $200 \mathrm{~km}^{2}$ e dista cerca de 30 km da cidade de Curitiba, no Estado do Paraná (Figura 1A). A bacia desenvolveu-se sobre as rochas metamórficas de alto grau do Terreno Luís Alves (Siga Jr., 1995) (Figura 1B). Foi primeiramente descrita como Formação Guaratubinha (Fuck et al., 1967), sendo seu preenchimento composto por sucessão de rochas vulcanossedimentares (Fuck et al., 1967; Daitx et al. 1979; Castro et al. 1993 e 1994; Siga Jr., 1995; Reis Neto et al., 2000).

Castro et al. (1993) propôs mudanças nos mapas geológicos anteriores, reduzindo drasticamente a área de rochas sedimentares, reclassificando-as como rochas vulcanoclásticas. Estes autores sugeriram nova estratigrafia para a bacia, subdividindo-a em cinco novas associações: associação sedimentar, vulcânicas (associação intermediária e ácida), vulcanoclásticas (associação superior e inferior).

Barão (2016) revisitou a bacia e definiu três novas formações abrangendo todas as suas 
rochas (Figura 2). São elas: a Formação Miringuava composta principalmente por conglomerados e subordinadamente arenitos finos e argilitos, caracterizando a formação basal de rochas da bacia; a Formação Vossoroca composta por andesitos com estru- tura de fluxo marcante; e as rochas vulcânicas ácidas da bacia denominada como Formação Serra do Salto, subdivida em três membros Osso da Anta (brechas vulcânicas e ignimbritos), Castelhanos (lapilli tufos e ignimbritos) e Escutador (riolitos a riodacitos).

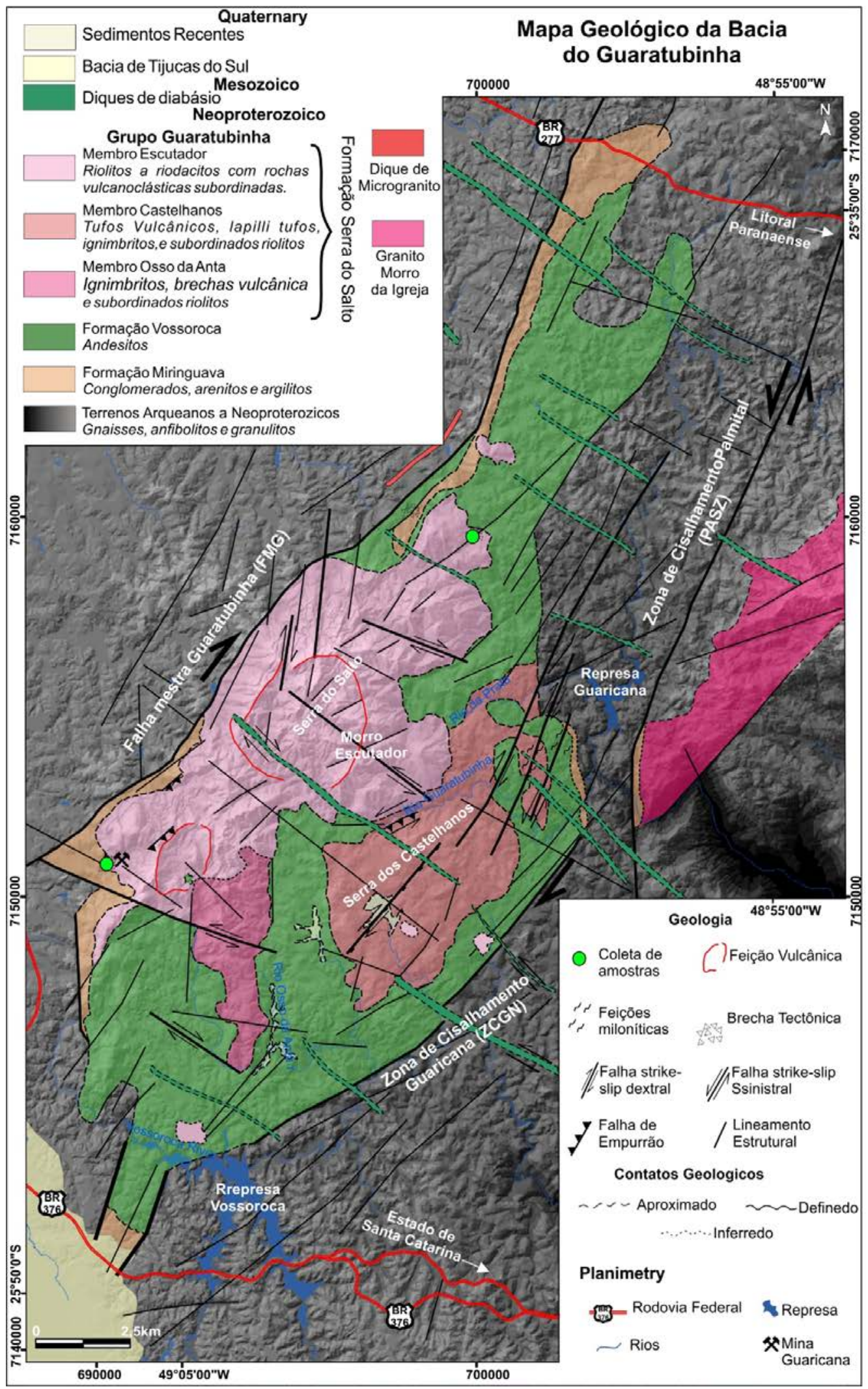

Figura 1. Mapa geológico da Bacia do Guaratubinha com o modelo digital de elevação (Projeto Pró-Atlântica, 2005). Os pontos verdes indicam onde foram coletadas as amostras de brechas tectônicas na unidade Membro Escutador. 
Barão (2016) definiu três eventos deformacionais distintos, associados principalmente à deformação strike-slip. O evento E1 está associado à formação da bacia e relacionado a estruturas de direção N25-45E (Figura 2), principalmente as estruturas controladoras das bordas sudeste e noroeste da bacia, denominadas respectivamente como Falha Mestra Guaratubinha (FMG) e a Zona de Cisalhamento Guaricana (ZCG). O evento E2 está ligado à reativação da Zona Cisalhamento Palmital (ZCPA) (Cury, 2009) durante o evento Cambriano que causou generalizada compressão na Bacia, bem como a ruptura da bacia na borda noroeste. O evento E3 estaria relacionado ao enxame de diques do Arco de Ponta Grossa, que secciona bacia na direção N35-45W, causando deslocamentos locais nas zonas FMG e ZCGN. No primeiro evento foram formadas as brechas tectônicas associadas ao hidrotermalismo caracterizadas nesse estudo.

A deformação strike-slip observada no evento E1 sugere que bacia se formou em contexto de bacia pull-apart, com a ativação da estrutura FMG em contexto transtensivo (Barão, 2016). Associado a esta fase formaramse os depósitos conglomeráticos nas bordas lestes e oeste, bem como o vulcanismo intermediário a ácido que ocorreu na bacia (Barão, 2016). A orientação da Bacia do Guaratubinha, bem com a sua sedimentação e vulcanismo sugestionam correlação com as bacias de Campo Alegre e Corupá em Santa Catarina (Kaul, 1997; Citroni et al., 2001; Barão, 2016).

\section{MATERIAIS E MÉTODOS}

A caracterização das brechas se deu a partir da coleta e descrição de amostras de brechas tectônicas hidrotermalizadas ao longo dos planos de falha. A coleta de amostras orientadas ocorreu na pedreira Guaricana e na porção norte da área, ambas localizadas nas proximidades da borda oeste da bacia (Figura 2). As brechas estão localizadas em riolitos do Membro Escutador formadas pela tectônica associada ao hidrotermalismo que ocorreu no evento E1 (Barão et al., 2017).

Foram selecionadas nove amostras para a análise petrográfica e microtectônica, a partir dessa análise foi possível definir o tipo de cimentação das brechas, a trama estrutural, os mecanismos de deformação, as fases de hidrotermalismo e o grau de maturidade dessas rochas. Geralmente a presença de fluidos hidrotermais, associados ao tectonismo, é relacionada à formação de depósitos hidrotermais como descrito em várias localidades (e.g.
Sibson, 1986; Laznicka, 1988; Jébrak, 1997; Lorilleux et al., 2002).

Jébrak (1997) compila diversos trabalhos descrevendo as brechas hidrotermais em veios mineralizados, estabelecendo os mecanismos formadores dessas brechas (Figura 3) e elucidando os mecanismos responsáveis pela sua geração, sendo eles: cominuição tectônica, brechação assistida por fluidos, redução de volume, expansão de volume, desgaste por abrasão, colapso e desgaste por corrosão. A comparação das brechas coletadas com os mecanismos de brechação resultou na caracterização dos processos envolvidos em sua formação. As fases diferenciadas de hidrotermalismo e tectônica foram interpretadas observando as relações de corte entre as distintas fases, bem como as diferentes assembleias minerais e as estruturas reconhecidas em seção petrográfica.

\section{RESULTADOS}

\section{Descrição e Caracterização das Brechas em Escala Mesoscópica}

As brechas são caracterizadas em campo como corpos estreitos e alongados que possuem até $1 \mathrm{~m}$ de espessura, definidos geralmente pela presença de planos de falha que tendem a ter direção preferencial entre N45-75W. Estas brechas estão, possivelmente, relacionadas a falhas antitéticas das principais falhas do evento E1 (Figura 3A e 3B). Configuram planos contínuos que apresentam por vezes indicadores cinemáticos como steps e slinckensides, com predominância de cinemática sinistral (Barão, 2016).

Os fragmentos encontram-se em maior proporção que a matriz, variando entre $10 \%$ e $20 \%$. Nos planos de falha, em que se concentram as brechas, os fragmentos (60$80 \%$ ) possuem forma angulosa e por vezes arredondada, têm dimensões variáveis entre 
0,1 e $4 \mathrm{~cm}$, são oligomíticos, sendo compostos principalmente por fragmentos de riólito e cristais de minerais resistatos ao cisalhamento, como o quartzo e feldspato alcalino (Figura 3C e 3D). Esses fragmentos são envoltos pela matriz de granulação fina a muito fina, composta por fragmentos de granulação menor $(<1 \mathrm{~cm})$ que os presentes no arcabouço da brecha. A cimentação que ocorre nessas rochas é evidente, possui cores variáveis entre cinza escura (Figura 3C), amarelo, vermelho (Figura 3D) e verde. No geral, a cimentação preenche os espaços vazios gerados pela cominuição mineral, podendo também preencher fraturas que seccionam os fragmentos líticos.
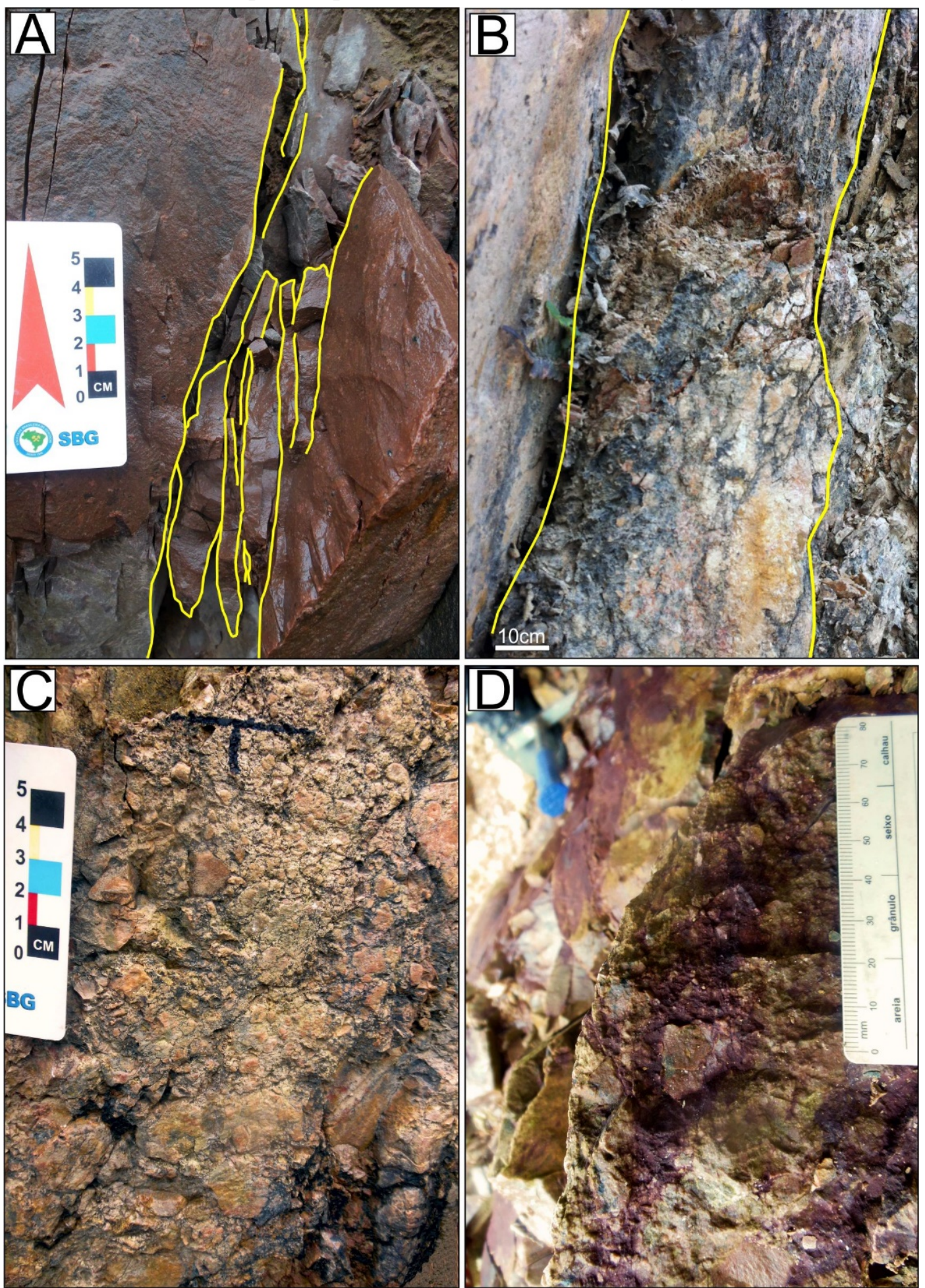

Figura 2. Detalhe dos planos brechados. A) Planos paralelos que geram o cisalhamento local; B) Fluxo cataclástico gerado pela cominuição contínua evoluindo para foliação cataclástica; C) Plano brechado de riólito, com fragmentos envoltos por cimento cinza escuro; D) Fragmentos da brecha riolítica em meio a matriz fina a muito fina, com cimento de cor vermelha a amarelada. 


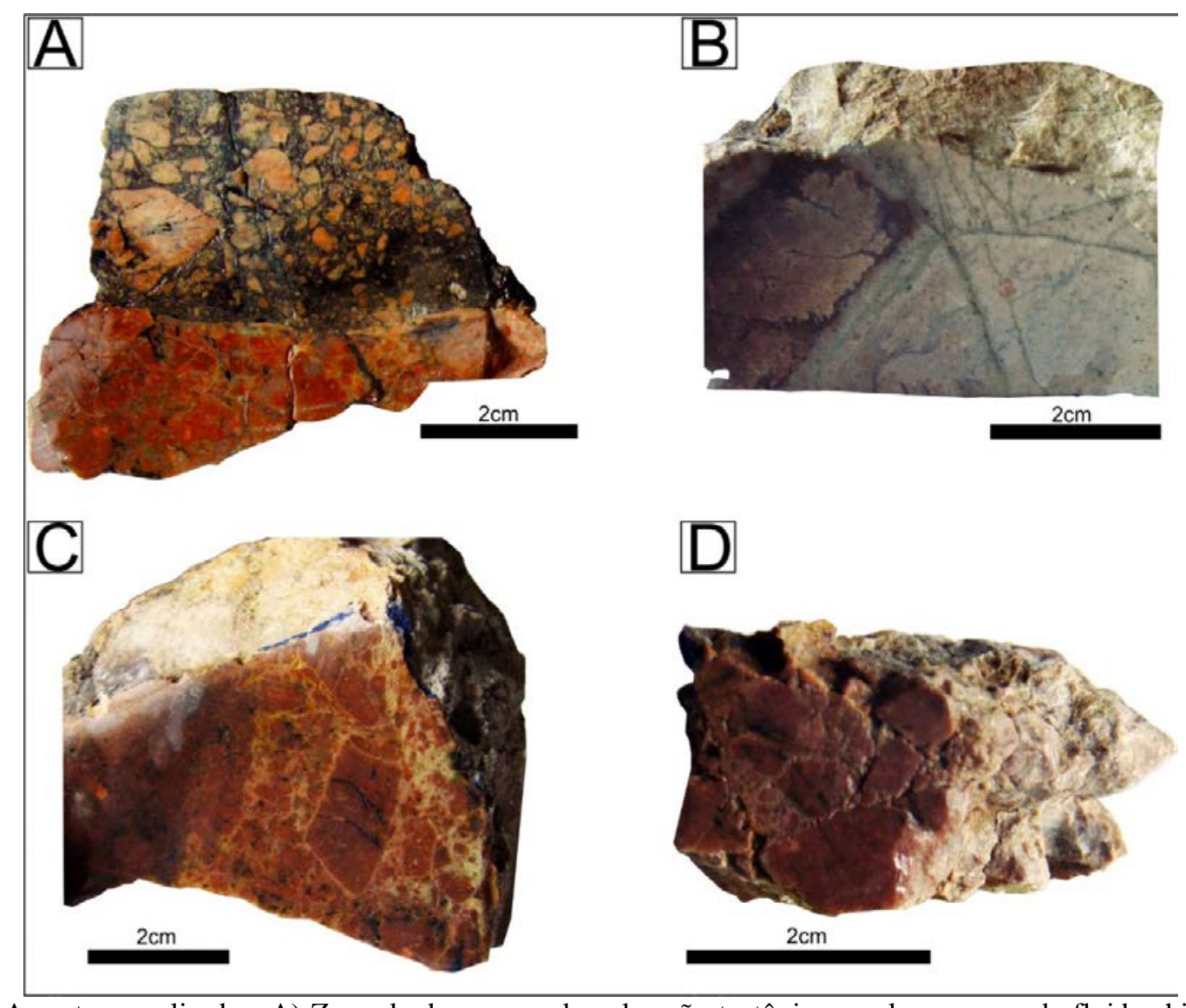

Figura 3. Amostras analisadas. A) Zona de dano causada pela ação tectônica e pela presença de fluidos hidrotermais; B) Amostra com ação hidrotermal de maior intensidade, alterando grande parte dos fragmentos, bem como preenchendo as fraturas pela cimentação clorítica; C) Amostra com fragmentos angulosos envoltos por cimento rico em clorita; D) Amostra de brecha sustentada por fragmentos angulosos cimentados por clorita.

A trama estrutural e o arranjo dos fragmentos perante a matriz são pouco evidentes em escala mesoscópica, os fragmentos não possuem direção preferencial de deformação, sendo cimentados aleatoriamente (Figura 4). A cimentação mais evidente é associada à percolação de óxidos (Figura 4A) e pela cimentação clorítica (Figuras 4B, 4C e 4D), de cor esverdeada que tende a seguir as fraturas principais das rochas. Na figura 4A a zona de dano é diferenciada, causando diferentes taxas de deformação em cada uma das porções.

\section{Arranjo Microestrutural das Brechas}

Assim como em escala mesoscópica, as tramas estruturais das brechas são diferenciadas ao microscópio, considerando a proporção de matriz e fragmentos líticos existentes em cada amostra. Os fragmentos riolíticos possuem estimativa visual variável entre $40-85 \%$, a matriz entre 20 $30 \%$ e o cimento entre 5-25\%. Essas proporções variam conforme a intensidade da deformação e do hidrotermalismo, exercidos de maneira diferenciada nessas rochas.

O arranjo dos fragmentos, em lâmina, é aleatório e se encontra disperso na matriz comi- nuída e cimentada por óxidos (Figuras 5A e B), clorita, quartzo e carbonato. O hábito, desses fragmentos, varia de anguloso a subarredondado. Estes fragmentos tendem a estar rotacionados devido a ação da brechação, não mantendo a posição original em que foram formados. A progressão da deformação e a cominuição generalizada faz com o que os grãos se reorientem segundo incipiente foliação marcada na matriz da rocha (Figura 5C).

A deformação tende a ser a mais intensa em algumas porções dessas brechas (Figuras 4A e 5C), cominuindo os fragmentos e transformandoos em matriz, ou então, gerando espaços vazios que hospedam a cristalização da clorita e a cimentação por hidróxidos (Figuras 5D). A deformação interna dos fragmentos varia de fraca a incipiente, devido à competência dos cristais presentes na assembleia mineralógica dos riolitos. Em alguns casos, onde a deformação é maior e há temperatura suficiente, ocorre a formação de subgrãos de quartzo (Figura 5E), que apresentam aspecto límpido, e devem ser resultado da interação do fluido hidrotermal com os fragmentos líticos. 

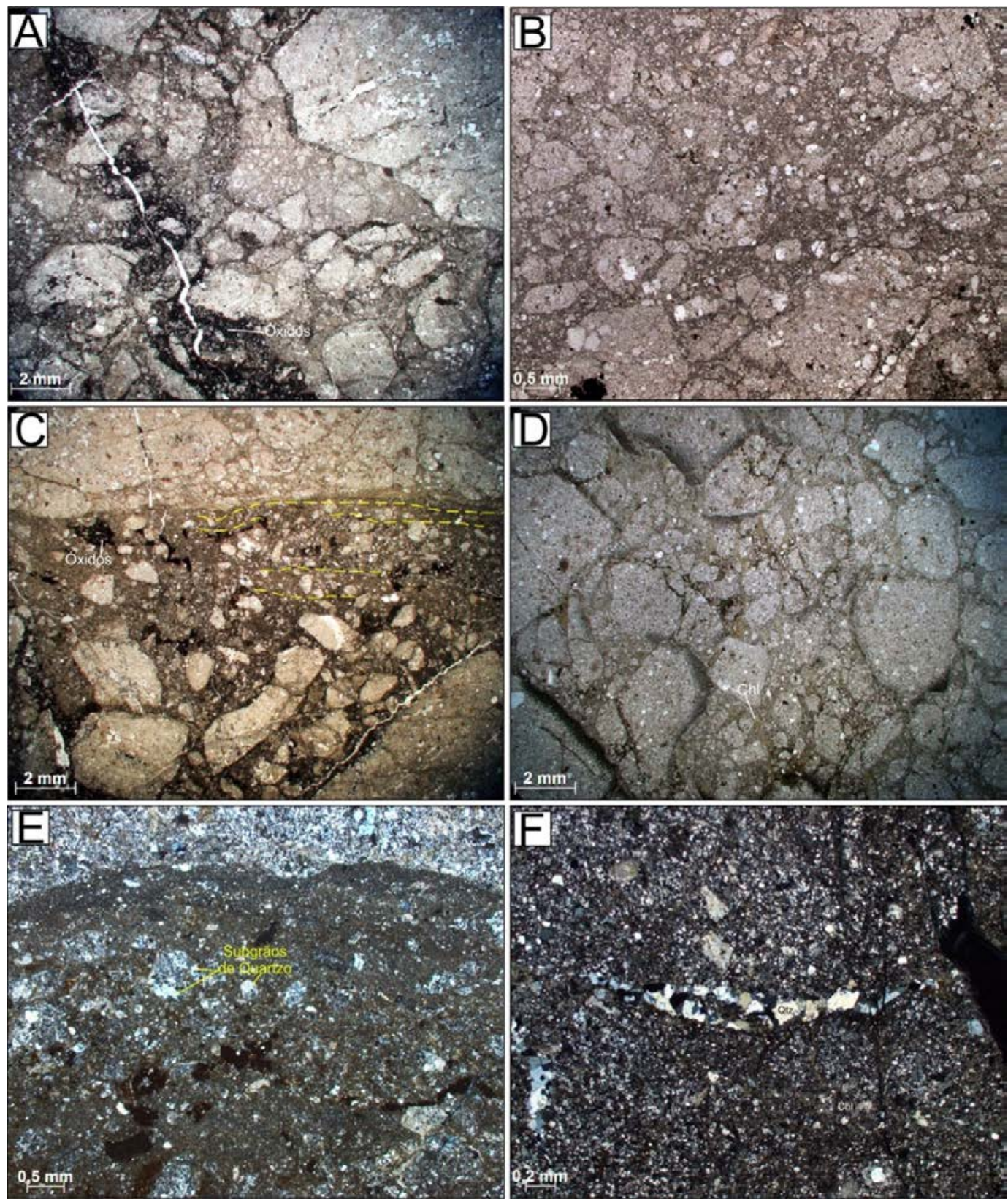

Figura 4. Fotomicrografias das tramas estruturais das brechas. A) e B) trama estrutural das brechas hidrotermalizadas com fragmentos líticos angulosos e arredondados dispostos em meio a matriz fina cimentada por óxidos e clorita; C) contato entre a região em que ocorre maior e menor deformação. Próximo ao contato se verifica a formação de incipiente foliação na matriz (tracejado de cor amarela), que tende a rotacionar os fragmentos líticos e reorientá-los; D) clorita cristalizada em fraturas e associada aos hidróxidos, o fluido hidrotermal deve ter facilitado a cominuição dos fragmentos de riólito; E) Clorita preenchendo os espaços vazios gerado pelo fraturamento hidráulico conferindo o caráter brechado para rocha; F) Feição de subgrão observada dentro de fragmento lítico, possivelmente causada pela reação da temperatura do fluido hidrotermal. Qtz: Quartzo, Chl: Clorita.

As venulações de quartzo são comuns e apresentam dimensões variáveis entre 0,5 e 8 $\mathrm{mm}$, exibindo cristais de granulação grossa (até 0,3mmm). Possuem contatos lobados e irregulares entre os cristais (Figura 5F), o que os diferencia do quartzo presente no riólito.

Os estilolitos estão presentes com frequência e são marcados por hidróxido de ferro ou material insolúvel, de cor cinza escura e avermelhada (Figura 6A e B). Utilizando-se da classificação de
Guzzeta (1984) e Andrews \& Railsback (1997) essas estruturas possuem forma alongada em picos irregulares e pontiagudos (Figura 6A) e em alguns casos são levemente onduladas (Figura 6B). As formas em pico estão associadas a pouca migração lateral dos limites de dissolução (Guzzeta, 1984), já as formas onduladas devem estar associadas a variação da taxa de migração, podendo estar associadas a presença de anteparo de maior resistência (Guzzeta, 1984). 
A presença de hidróxidos está relacionada a formação de iddingsita e de clorita (Figuras 6C a 6E). A iddingsita sob luz polarizada possui cor castanho avermelhada, não possui hábito definido, e ocorre preenchendo fraturas associadas aos óxidos, por vezes acaba englobando fragmentos líticos e cristais minerais resistatos (Figura 6C). A clorita quando possui espaço, bem como temperatura e a composição do fluido compatível para sua cristalização, tende a possuir o hábito fibroradiado (Figura 6D). A sua ocorrência também se dá sobrecrescida sobre fragmentos e
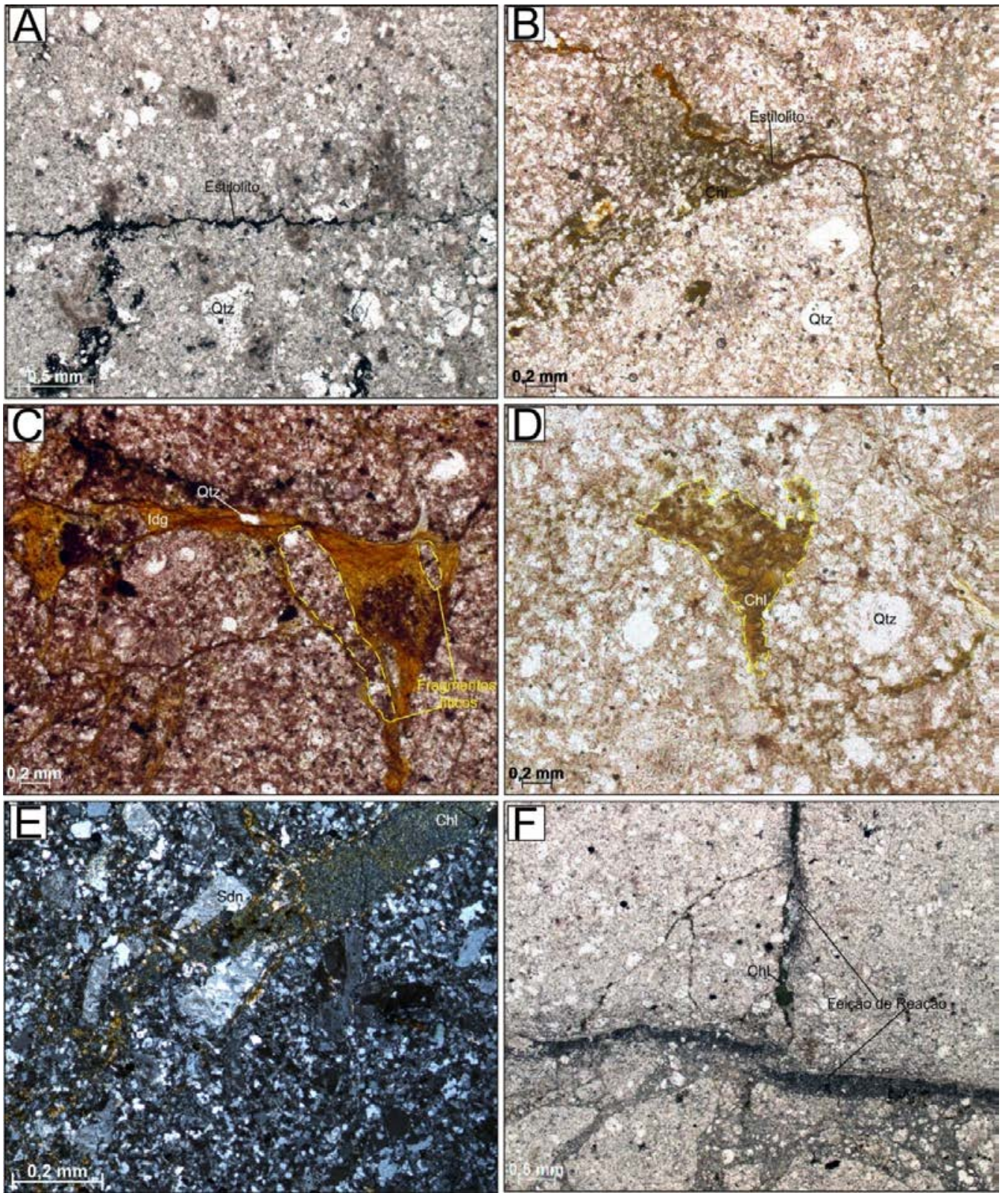

Figura 5. Fotomicrografias das estruturas observadas nas brechas. A) Estilolitos, marcados por hidróxido de ferro cinza escuro, classificados como picos irregulares e pontiagudos (Guzeta, 1984); B) Estilolitos de óxido de ferro de cor avermelhada, classificado como levemente ondulados. Esses estilolitos tendem a se redirecionar devido a presença de anteparo, neste caso um fragmento lítico; C) Clorita anédrica envolvendo fragmentos líticos e cristais de quartzo; D) Agregado de clorita fibroradiada desenvolvido no espaço gerado pela cominuição da rocha; E) A cloritização causando a ruptura dos cristais de sanidina; F) Bordas de corrosão causada pela interação do fluido hidrotermal e do fragmento de riólito. Qtz: Quartzo, Chl: Clorita, Sdn: Sanidina, Idg: iddingsita. 


\section{Fases de Brechação}

A partir da análise petrográfica foi possível estabelecer a relação entre cada uma das fases de brechação, obtendo desta forma quatro

\section{DISCUSSÕES}

fases de brechação distintas, detalhadas na tabela de correlação (Figura 7). Foram relacionadas as fases e o seu indicador mineral ou estrutura.

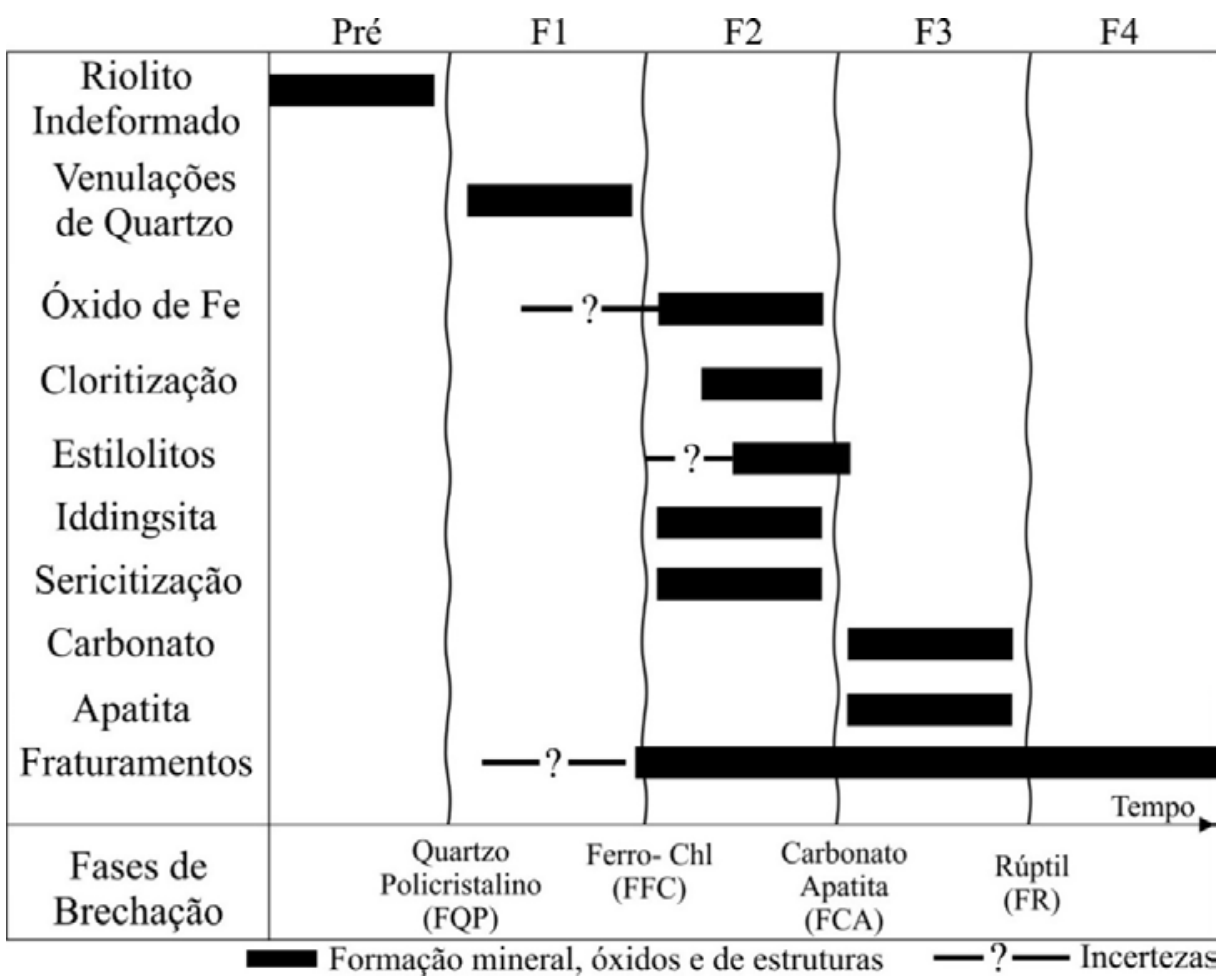

Figura 6. Fases hidrotermais definidas pela relação entre os eventos de deformação e a formação de minerais.

\section{Fase Quartzo Policristalino (FQP)}

A fase de quartzo policristalino (FQP) caracteriza-se como a primeira fase deformacional, sendo caracterizada por vênulações locais de quartzo com padrão policristalino. Apresentam dimensões milimétricas $(0,5$ a 0,8 $\mathrm{mm}$ ), o que dificulta a sua observação em escala mesoscópica. Essas venulações tendem a englobar os fragmentos de riolitos, deixando-os isolados da matriz da rocha (Figura 8A).

O quartzo possui moderada a forte extinção ondulante, resultado do processo de dislocation glide em condições de baixas temperaturas (300-400 ${ }^{\circ} \mathrm{C}$ ) segundo Paschier \& Trow (2005). Nesse processo ocorre o predomínio do mecanismo de recristalização dinâmica, podendo ocorrer feições de bulging associadas ao fenômeno (Stipp et al., 2002), o que justifica por vezes a presença de feições lobadas entre os novos cristais formados.

Os fragmentos riolíticos, englobados pelas venulações, resistiram em grande parte a deformação causada pela formação dos veios, não apresentando feições deformacionais distintas e mantendo a mesma trama vulcânica pré-existente. No entanto, as bordas desses fragmentos encontram-se, por vezes, alteradas pelo processo de sericitização. As venulações de quartzo bem como os fragmentos são afetadas pela segunda fase de deformação (FFC) em que ocorre a precipitação de óxidos e a formação da clorita, que causa a brechação generalizada e sobrecrescimento da clorita sobre as venulações e fragmentos líticos.

\section{Fase FE-Clorita (FFC)}

Representa a fase de brechação mais expressiva que afetou essas rochas. Nessa fase ocorre a implantação do regime de percolação de fluidos relacionados ao fraturamento hidráulico da rocha, que fragmentou e cimentou as brechas (Figura 8B). A fragmentação imposta por essa fase está associada a diversos mecanismos de brechação, mas principalmente associada à brechação assistida pelo fluido hidrotermal, o que causa fragmentação diferenciada em cada brecha. Os fragmentos gerados nessa fase são geralmente angulosos e os hidróxidos tendem a englobar os fragmentos e cristais resistatos (Figura 8B). 

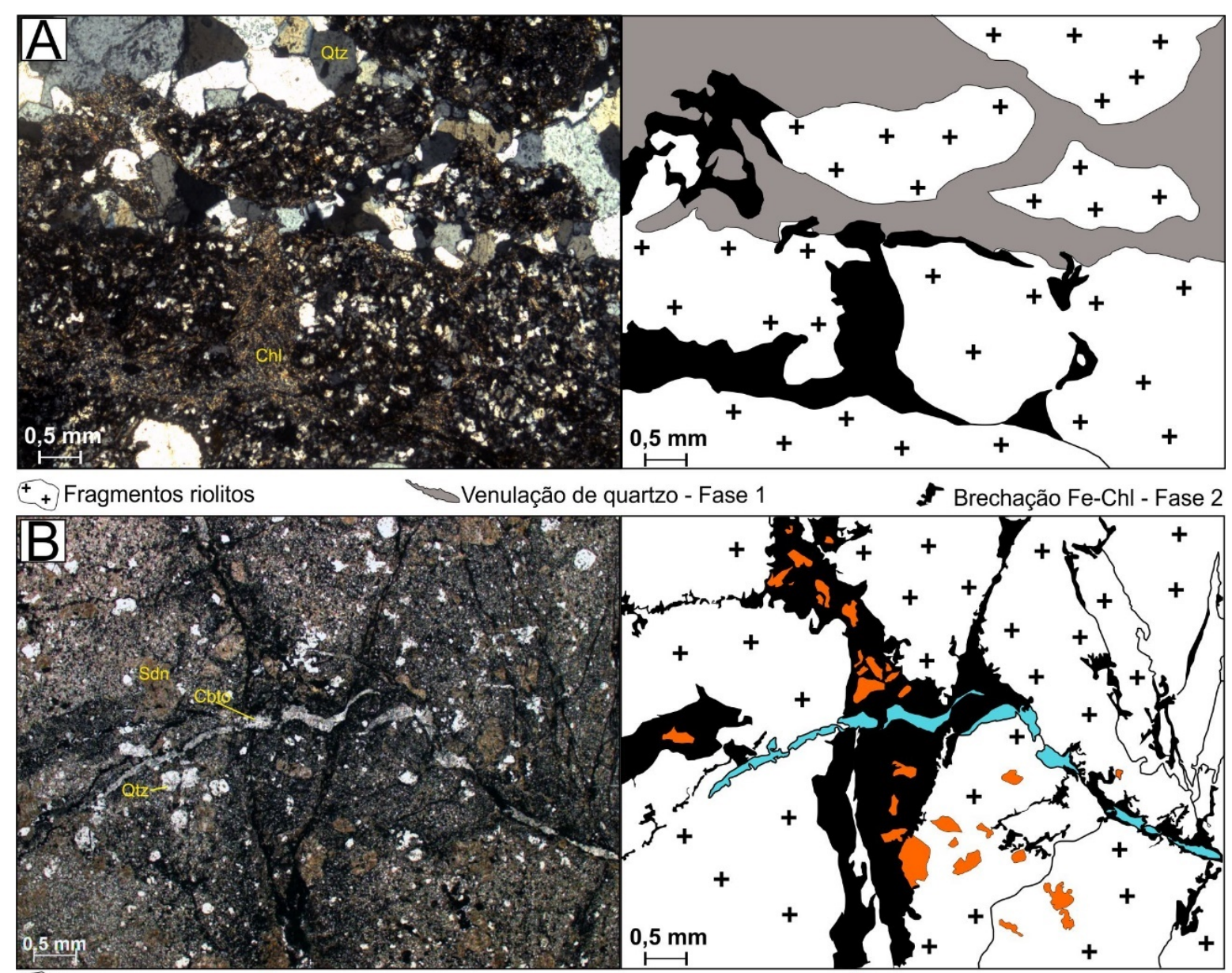

+ + Fragmentos riolitos OFragmentos mineiras \$ Brechação Fe-Chl - Fase 2 SVenulação carbonática - Fase 3

Figura 7. Fotomicrografia da relação de corte entre as fases distintas de deformação. A) relação entre a primeira fase (FQP) e a segunda fase de brechação (FFC), com a formação de vênulas de quartzo e sobreposição da clorita. B) relação entre as fases FFC e FCA, com a formação de venulações carbonáticas sobrepondo a cloritização e os óxidos. Chl: Clorita; Qtz: Quartzo; Sdn: Sanidina; Cbto: Carbonato.

A Fase Fe-Chl, além de associada aos hidróxidos, está diretamente ligada a formação de sericita, iddingsita (Figura 6C) e clorita fibroradiada (Figura 6D).

A presença da clorita confere a cor esverdeada a essas rochas (Figura 4B), e cinza escura a avermelhada quando há predomínio do hidróxido de ferro.

A forte alteração hidrotermal causada pela presença desses fluidos gera feições de corrosão nos fragmentos de maior resistência (Figura $6 \mathrm{~F}$ ), bem como rotação dos grãos. Lorilleux (2002) caracteriza esse fenômeno como mudança do estágio imaturo para o maturo.

$\mathrm{O}$ fraturamento é intenso nessa fase e sempre se encontra associada a presença do hidróxido de ferro. A formação da clorita nessa situação está associada a adição de $\mathrm{MgO}$ no fluido hidrotermal, o que leva a cristalização da clorita (Wintsch et al., 1995).

Os estilolitos gerados nessa fase seccionam os fragmentos líticos e fenocristais de feldspato
(Figura 9A), sendo associados a fenômenos da dissolução, tendo sido formados em momento final e associados ao fenômeno de dissolução por pressão (Renard et al., 2008).

O mecanismo causa a dissolução dos fragmentos de riólito e cristais de quartzo durante a sua formação o que dá a forma diferenciada a essas estruturas.

\section{Fase Carbonato Apatita (FCA)}

A Fase Carbonato-Apatita (FCA) superimposta a fase FFC (Figura 7), forma venulações que aproveitaram do espaço gerado pela fase anterior, sobrecrescendo sobre as feições brechóides e fraturas desenvolvidas pela FFC (Figura 8B e 9B).

O carbonato, no geral, não apresenta cristais bem formados, tendo seu caráter microcristalino marcante, o que dificulta a observação de deformações internas e a geminações dos cristais. As venulações possuem 1 a $4 \mathrm{~mm}$ de comprimento e, por vezes, tendem a ter comportamento de 
estilolito levemente ondulado (Figura 8B).

Associada às venulações hidrotermais se observa a presença da apatita com hábito euédrico a arredondado (Figura 9B), que engloba fragmentos da matriz e cristais resistentes de quartzo.
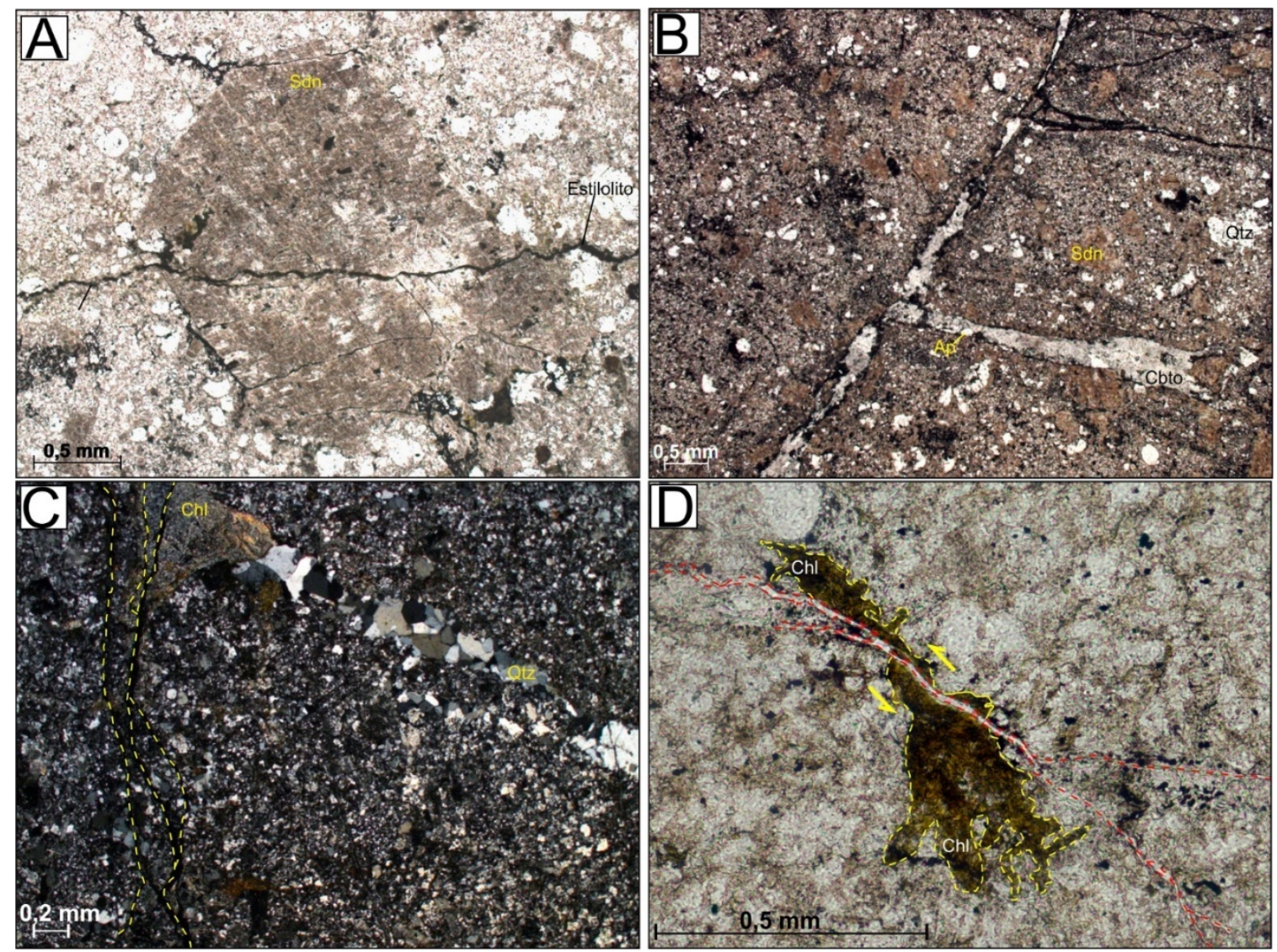

Figura 8. Fotomicrografias das estruturas geradas pelas fases de brechação. A) Estilolito pontiagudo seccionando fenocristal de sanidina; B) Venulação de carbonato aproveitando espaço gerado pela fase de brechação anterior; C) Microfraturas (tracejado amarelo), geradas durante a fase final rúptil seccionando a clorita; D) Microfratura (tracejado vermelho) seccionando a clorita, marcando a movimentação sinistral aparente. Sdn: Sanidina; Cbto: Carbonato; Qtz: Quartzo; Chl: Clorita; Ap: Apatita.

\section{Fase Rúptil (FR)}

A fase rúptil (FR) é marcada pela formação generalizada de microfraturas sem a percolação ou com pouca percolação do fluido hidrotermal, afetando as diferentes fases anteriores. As fraturas possuem o caráter rúptil com espaçamento submilimétrico $(0,1$ a 0,2$)$ e baixa penetratividade (Figura 9C) e ocorrência restrita. As fraturas, no geral, são curvilíneas e pouco contínuas.

O fraturamento tende a desenvolver microfalhas, com o deslocamento de cristais formandos em outras fases, como observado na figura 9D em que a clorita, formada na segunda fase, encontra-se seccionada pela fase rúptil, marcando assim evento sem influência hidrotermal e desenvolvimento mineral.

\section{Mecanismos de Brechação}

Utilizando-se da classificação proposta por Jébrak (1997) foram identificados quatro tipos distintos de mecanismos de brechação, sumarizados na Figura 10, para cada seção petrográfica descrita. Os quatro tipos de mecanismos devem ter atuado de maneira concomitante com a implantação do regime de cominuição tectônica assistido pelo hidrotermalismo, sendo principalmente associados à segunda fase de brechação (FFC) e a última (FR). Segundo Jébrak (1997) os mecanismos de cominuição tectônica, brechação assistida por fluidos e a corrosão por abrasão constituem os mecanismos mais comuns em depósitos minerais, por isso mais fáceis de serem observados em brechas hidrotermais.

\section{Cominuição tectônica e Desgaste por Abrasão}

A cominuição tectônica e o desgaste por abrasão tendem a atuar em conjunto com os mecanismos causadores de brechas. Esses mecanismos ocorrem pela fricção de 
fragmentos líticos, associada a zonas de falhas sismogênicas formadas no topo da crosta entre 10-15 km de profundidade (Sibson, 1977 e 1983). Nesse processo a propagação de fraturas e o desgaste por abrasão são responsáveis pela cominuição tectônica (Jébrak, 1997).

A fragmentação dos grãos, gerada pela ação conjunta dos dois mecanismos de brechação, causa a progressiva redução da granulação da rocha de falha, como observado na Figura 2.5B.

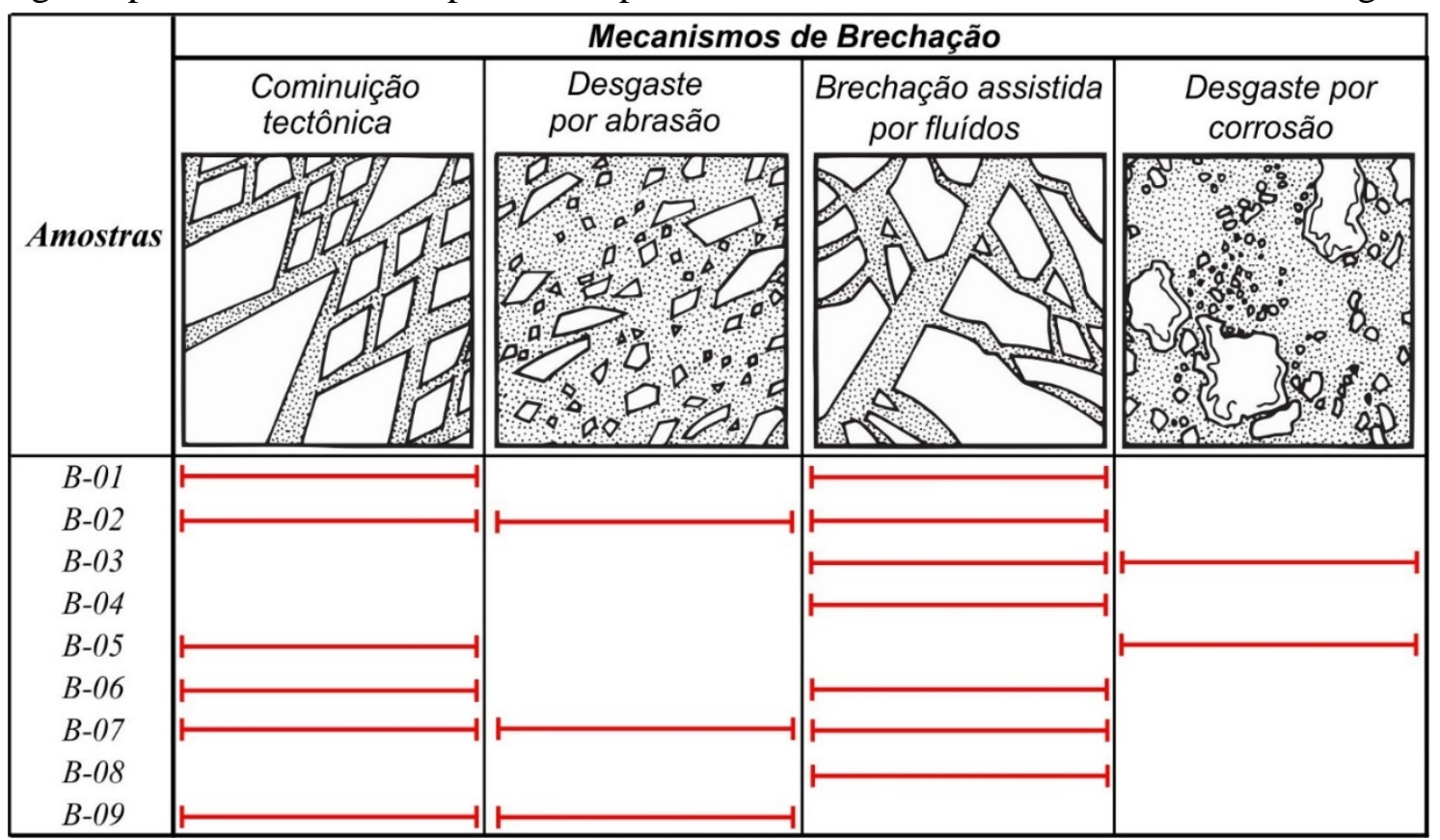

Figura 9. Sumarização dos mecanismos de brechação identificados em cada uma das seções petrográficas, comparado aos mecanismos compilados por Jébrak (1997) em brechas formadas ao longo de veios hidrotermais.

Consequentemente ocorre a rotação dos grãos e a reorientação mineral paralela a direção de movimentação da falha e perpendicular ao principal tensor (Jébrak, 1997). Pode ocorrer também a recristalização mineral, definida pela formação subgrãos em cristais de quartzo (Figura 5E). O tamanho dos grãos, gerados nesse processo, é altamente variável, bem como sua disposição (Jébrak, 1997), porém a morfologia dos cristais tende a ser angulosa (Figuras 5A e 11A). Essa tendência se justifica pela formação de fraturas de tensão internas aos fragmentos, que confere aspecto anguloso aos fragmentos (Sammis et al., 1986).

\section{Brechação Assistida por Fluidos}

A brechação assistida por fluidos está relacionada a pressão exercida pela percolação de fluidos hidrotermais, o que causa a propagação de microfraturas. Segundo Beach (1980) o regime extensional é imposto para a propagação das fraturas e percolação de fluidos. Em zonas de falha a presença de fluido aquoso é confirmado pela presença de veios, brechas e alterações hidrotermais, sendo dependentes da taxa de deformação exercida (Wiltschko \& Smith, 1992). Durante a deformação o mecanismo leva a inserção de fluidos quentes gerando fragmentos mais arredondados, quando comparado aos gerados pela cominuição mineral e o desgaste por abrasão.

No caso apresentado o aumento da pressão causa a fragmentação desordenada da rocha, fazendo com que os fragmentos sejam envoltos pelos fluidos hidrotermais (Figuras 6C e 11B), desagregando os fragmentos da rocha parental e cimentando os fragmentos riolíticos. A presença de estilolitos deve estar associada a esse mecanismo, estando associado a dissolução por pressão (Guzzeta, 1984; Andrews \& Railsback, 1997; Renard et al., 2008) causada pela pressão de fluidos exercida durante a implantação do regime hidrotermal nessas rochas.

\section{Desgaste por Corrosão}

O desgaste por corrosão acontece na litosfera devido a diversos fatores como: a brechação magmática, instalação de corpos graníticos e a ação hidrotermal (Jébrak, 1997). Esse tipo de reação ocorre quando se atinge o regime limitado de difusão, ou seja, grande parte da matriz é consumida, fazendo com que as bordas dos fragmentos fiquem desprotegidas, facilitando sua dissolução 
(Jébrak, 1997). Nesse processo ocorre o extremo desequilíbrio entre a rocha e o fluido, sendo a taxa de alteração de dissolução limitada pela reação química que ocorre durante o processo. Esse processo gera fragmentos que tendem a ser mais arredondados, podendo adquirir forma esférica (Jébrak, 1997).
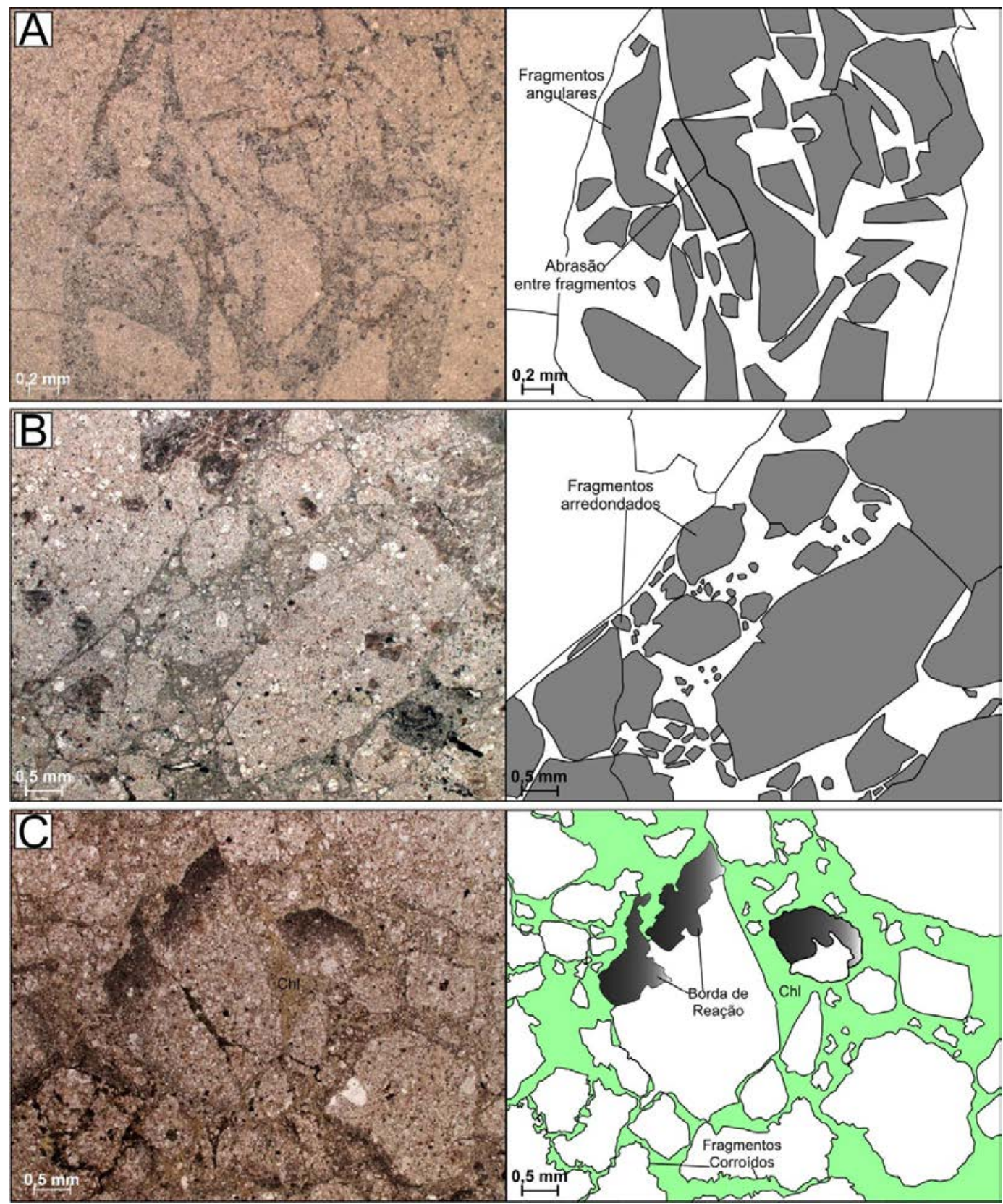

Figura 10. Fotomicrografias e ilustrações esquemáticas exemplificando os principais mecanismos de brechação identificados. A) Cominuição e desgaste por abrasão dos fragmentos líticos e posterior preenchimento por fluidos hidrotermais; B) Brechação assistida por fluidos gerando fragmentos parcialmente orientados, porém mais arredondados que os gerados por cominuição; C) feições geradas pelo desgaste por corrosão, formando nas bordas dos fragmentos, feições reativas com o líquido hidrotermal.

\section{Evolução das Brechas}

A evolução das brechas pode ser definida pela diferenciação dos mecanismos de brechação identificados. Esta evolução está relacionada a diminuição da energia mecânica e o aumento do desequilíbrio químico entre o fluido e a rocha (Figura 12). A diferente morfologia dos fragmentos (Dr) e a distribuição do tamanho das partículas (Ds) podem ser utilizados como parâmetros geométricos e fractais para a definição dos diferentes estágios de formação de uma brecha hidrotermal (Jébrak, 1997).

As brechas são inicialmente relacionadas a deformação associada ao tectonismo, passando pelos mecanismos de brechação mecânicos (desgaste por abrasão e cisalhamento), que 
formam fragmentos angulosos em meio a matriz de granulação fina e cominuída. A medida que a percolação de fluidos aumenta, ocorre a redução da energia mecânica e o aumento do desequilíbrio químico. Consequentemente a fragmentação é diferenciada (Figura 12), tendendo a formar fragmentos com morfologia arredondada, que em processo de brechação assistida por fluidos permite a cimentação da brecha, com a precipitação de hidróxidos e clorita. O contínuo aumento do desequilíbrio químico forma morfologias diferenciadas, com desgaste por corrosão e bordas reativas nos fragmentos.

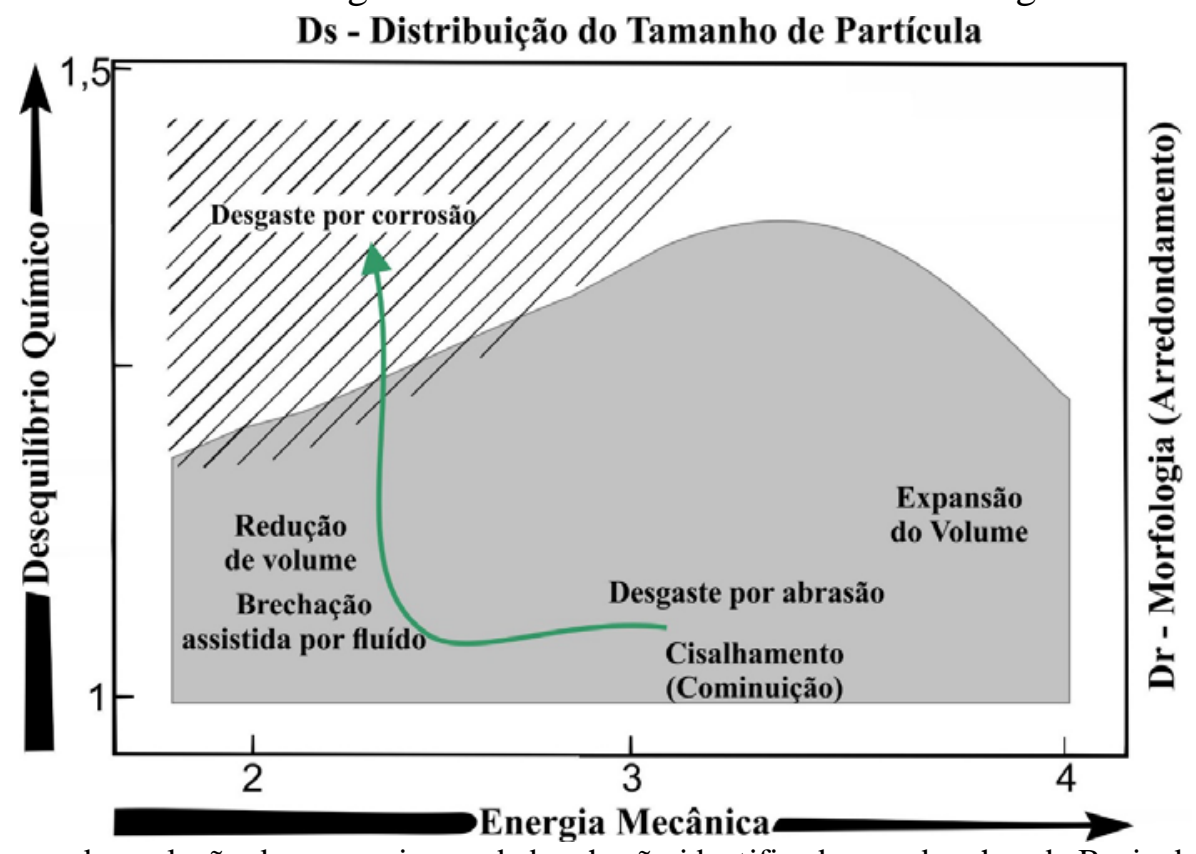

Figura 11. Diagrama da evolução dos mecanismos de brechação identificados nas brechas da Bacia do Guaratubinha. O diagrama relaciona o arredondamento de dimensão fractal (Dr) vs a distribuição do tamanho das partículas (Ds), com os campos dos diferentes tipos de brechas em zona hidrotermais. A zona com linhas paralelas (desgaste por corrosão) foi estipulada em rochas formadas nos depósitos tipo Olympic Dam e Don Rouyn (Jébrak, 1997). A zona sobreada (brechas mecânicas) foi medida no depósito de Cirotan (Genna et al., 1996) e os valores estipulados derivados de Grady \& Kipp (1987). Modificado de Jébrak (1997).

\section{RESULTADOS E DISCUSSÕES}

As brechas descritas na Bacia do Guaratubinha estão relacionadas ao evento de deformação E1, no qual tectônica e hidrotermalismo ocorreram concomitantemente nas rochas riolíticas do Membro Escutador. Evidências em campo e a descrição microestrutural de amostras mostraram que:

(1) As brechas passaram por quatro fases distintas de deformação e hidrotermalismo: A primeira fase relacionada a venulações de quartzo (Fase Quartzo Policristalino - FQP); a segunda relacionada a percolação de fluidos ricos em hidróxidos e com a precipitação da clorita (Fase Fe-Chl - FFC); a terceira relacionada a venulações de carbonato associada a apatita (Fase
Carbonato-Apatita - FCA); e a quarta associada a fase rúptil posterior, onde predominou o fraturamento (Fase Rúptil - FR);

(2) Conexo principalmente às fases FFC e FR, foram observados quatro diferentes mecanismos de brechação: cominuição, desgaste por abrasão, brechação assistida por fluidos e desgaste por corrosão;

(3) Observou-se a progressão dos mecanismos brechação, evoluindo de processos inicialmente mecânicos (cominuição e desgaste por abrasão), para intermediários associados a fluidos (brechação assistida por fluidos) e desequilíbrio químico, gerando feições de corrosão nos fragmentos líticos.

\section{AGRADECIMENTOS}

Os autores agradecem ao CNPq pelo financiamento do projeto "Tectônica, sedimentação e magmatismo na Bacia do Guaratubinha, PR”, n 481065/2013-0. Ao Programa de Pós-Graduação em Geologia da Universidade Federal do Paraná e a CAPES pela bolsa de mestrado ao primeiro autor. À Mineração Guaricana pelo acesso à mina. Aos laboratórios LABAP, LAMIR por toda a infraestrutura cedida. 


\section{REFERÊNCIAS}

ALMEIDA F. F. M. DE. Diferenciação tectônica da Plataforma Brasileira. In: CONGRESSO BRASILEIRO DE GEOLOGIA, Salvador, 23, 1969, Anais...Salvador: Sociedade Brasileira de Geologia, p. 29-46.

ANDREWS, L. M. \& RAILSBACK, L .B. Controls on stylolite development, morphologic, lithologic, and temporal evidence from bedding parallel and transverse stylolites from U.S. Appalachians. Journal of Structural Geology, v. 105, p. 59-73, 1997.

BARÃO, L. M. Arcabouço Estratigráfico-Estrutural da Bacia Guaratubinha e Deformações Associadas, Sudeste do Paraná. Curitiba. 2016. 135p. Dissertação (Mestrado em Geologia Exploratória) - Programa de Pós-Graduação em Geologia, Universidade Federal do Paraná.

BASEI, M. A. S.; SIGA JR., O.; REIS NETO, J. M. O Batólito Paranaguá. Proposição, idade, considerações petrogenéticas e implicações tectônicas. Natal. In: CONGRESSO BRASILEIRO DE GEOLOGIA, 4, 1990. Natal. Anais...Natal: Sociedade Brasileira de Geologia, p. 16841699.

BEACH, A. Numerical models of hydraulic fracturing and the interpretation of syntectonic veins. Journal of Structural Geology, v. 2, p.425-438, 1980.

CITRONI, S. B.; BASEI, M. A. S.; SIGA JR., O.; REIS NETO, J. M.. Volcanism and Stratigraphy of the Neoproterozoic Campo Alegre Basin, SC, Brasil. Anais da Academia Brasileira de Ciências, v. 73, p. 581-597, 2001.

CASTRO, N. A.; REIS NETO, J. M.; ASSINE, M. L. Rochas Vulcanogênicas da Formação Guaratubinha, PR. In: SIMPÓSIO SUL BRASILEIRO DE GEOLOGIA, 5, 1993, Curitiba. Anais...Curitiba: Sociedade Brasileira de Geologia, p. 43-44.

CASTRO N.; PINHEIRO JR V.; REIS NETO J.M. Formação Guaratubinha: A importância das rochas vulcanoclasticas. In: CONGRESSO BRASILEIRO DE GEOLOGIA, 38, 1994, Camboriú, Boletim de Resumos Expandidos... Camboriú: Sociedade Brasileira de Geologia v. 3, p. 72-74.

CURY, L. F. Geologia do Terreno Paranaguá. São Paulo, 2009, 202p. Tese (Doutorado em Geociências), Instituto de Geociências, Universidade de São Paulo.

DAITX, E. C. Mapa geológico, folhas parciais de São José dos Pinhais - SG-22-X-D-IV e Paranaguá - SG-22-X-D-V. Escala 1:100.000. In: Carvalho, M. A. da S. Projeto geoquímica na área de Guaratubinha-Píen, relatório final, v.1, 1979.

FRANK, F. C. \& LAWN, B. R. On the theory of Herzian fractures. Proceedings of the Royal Society of London, v. 299, p. 291-306, 1967.

FUCK, R. A.; MARINI, O. J.; TREIN, E. A Formação Guaratubinha. Boletim Paranaense de Geociências, v. 23, p. 237-256, 1967.

GUZZETA, G. Kinematics of stylolite formation and physics of the pressure-solution process. Tectonophysics, v.101, 383394, 1984.

JÉBRAK, M. Hydrothermal breccias in vein-type ore deposits: A review of mechanism, morphology and size distribution. Ore Geology Reviews, v.12, 111-134, 1997.

KAUL, P. F. T. O magmatismo na Serra do mar e Adjacências (Sul do Brasil) no final do Proterozoico e seus condicionantes tectônicos. São Paulo, 1997, 331p. Tese (Doutorado em Geociências), Instituto de Geociências, Universidade de São Paulo.

LAZNICKA, P. Breccias and Coarse Fragmentites.
Petrology, Environments, Associations, Ores. Elsevier, Developments in Economic Geology, v. 25, 832p., 1989.

LORILLEUX, G.; JÉBRAK, M.; CUNEY, M.; BAUDEMONT, D. Polyphase hydrothermal breccias associated with unconformity-related uranium mineralization (Canada): from fractal analysis to structural significance. Journal of Structural Geology, v. 24, p. 323-328, 2002.

PASSCHIER, C. W. \& TROW, R. A. J. Microtectonics. Spinger Berlim New York, 366p, 2005.

REIS NETO, J. M.; VASCONCELLOS, E. M. G.; BITTENCOURT, C. Guaratubinha Formation - PR: petrographic characterization of volcaniclastic rocks. Revista Brasileira de Geociências, v. 30, p. 371-374, 2000.

RENARD, F., GRATIER, J.P., SCHMITTBUHL J.; MEAKIN P.; MERINO, E. The three-dimensional roughness of stylolites in limestones: roughness analysis and possible genetic implications. Journal of Geophysical Research, American Geophysocal Union (AGU), v. 109, p. 03209, 2008.

SAMMIS, C. G.; Osborne, R.; Anderson, J.; Banerdt, M.; White, P. A self-similar model for the kinematics of gouge deformation. Pure Applied Geophysics, v. 125, 777-812, 1986.

SIBSON, R. H. Fault rocks and fault mechanisms. Journal of Geological Society of London, v. 133, p. 191-213, 1977.

SIBSON R. H. Brecciation Process in Fault Zones: Inferences from Earthquake Rupturing. PAGEOPH, v. 124, p. 160-175, 1986.

SIGA JR., O. Domínios Tectônicos do Sudeste do Paraná e Nordeste de Santa Catarina: Geocronologia e Evolução Crustal. São Paulo, 1995, 232p. Tese (Doutorado em Geociências), Instituto de Geociências, Universidade de São Paulo.

SIGA JR., O., BASEI, M. A. S., SATO, K., CORDANI, U. G., CITRONI, S. B. U-Pb and Sm-Nd Isotopic Studies of Campo Alegre and Guaratubinha Volcanosedimentary Basins, Southern Region. In: CONGRESSO INTERNACIONAL DE GEOLOGIA, 31, 2000, Rio de Janeiro. Anais... Rio de Janeiro: Sociedade Brasileira de Geologia, 4p.

STIPP, M., STÜNITZ, H., HEIBRONNER, R., SCHMID S. M. The eastern Tonale fault zone: “a natural laboratory" for crystal plastic deformation of quartz over a temperature range from 250 to $700^{\circ} \mathrm{C}$. Journal of Structural Geology, v. 24, p. 1861-1884, 2002

TEIXEIRA, A. L., GAUCHER, C., PAIM, P. S. G., FONSECA, M. M., PARENTE, C. V., SILVA FILHO, W. F., ALMEIDA, A. R., Bacias do estágio da transição da Plataforma Sul-Americana. In: MANTESSO-NETO, V., BARTORELLI, A., CARNEIRO, C. D. R., BRITO-NEVES, B. B. DE B. (Coords), Geologia do Continente SulAmericano. Evolução da Obra de Fernando Flávio Marques de Almeida. São Paulo, p. 487-536, 2004.

WILTSHKO, D. V. \& SMITH, R. E. Development of abnormal fluid pressures beneath a ramping thrust sheet: Where's the evidence? Geological Society of American Abstract Programs, v. 24, n. 112, 1992.

WINTSCH, R. P., CHRISTOFFERSEN, R., KRONENBERG, A. K. Fluid-rock reaction weakening of fault zones. Journal of Geophysical Research, v. 100, n. B7, p. 13.021-13.032, 1995.

Submetido em 8 de setembro de 2016 Aceito em 27 de setembro de 2017 